\section{JURNAL EKONOMI EFEKTIF}

ISSN : $2622-8882$, E-ISSN : 2622-9935

Jurnal Ekonomi Efektif, Vol. 3, No. 2, Januari 2021 @Prodi Manajemen Fakultas Ekonomi Universitas Pamulang

\title{
PENGARUH LINGKUNGAN KERJA DAN MOTIVASI TERHADAP KINERJA PEGAWAI PADA DINAS KEPENDUDUKAN DAN PENCATATAN SIPIL KOTA TANGERANG
}

\author{
M. Hilman Zainuri \\ Universitas Pamulang, Tangerang Selatan, Banten, Indonesia \\ dosen02564@unpam.ac.id
}

Manuskrip: Sept-2020; Ditinjau: Okt-2020; Diterima: Okt-2020; Online: Jan-2021; Diterbitkan: Jan-2021

\begin{abstract}
ABSTRAK
Penelitian ini bertujuan untuk mengetahui pengaruh lingkungan kerja terhadap kinerja pegawai pada Dinas Kependudukan dan Pencatatan Sipil Kota Tangerang. Untuk mengetahui pengaruh motivasi terhadap kinerja pegawai pada Dinas Kependudukan dan Pencatatan Sipil Kota Tangerang. Untuk mengetahui pengaruh lingkungan kerja dan motivasi terhadap kinerja pegawai pada Dinas Kependudukan dan Pencatatan Sipil Kota Tangerang. Metode penelitian yang digunakan adalah metode kuantitatif dengan teknik pengumpulan data menggunakan instrument kuesioner. Populasi dalam penelitian ini adalah seluruh pegawai Dinas Kependudukan dan Pencatatan Sipil Kota Tangerang, teknik sampel yang digunakan adalah menggunakan rumus slovin sehingga sampel yang didapatkan berjumlah 85 responden. Data yang diperoleh dari penelitian ini dianalisis menggunakan metode statistik dengan bantuan program SPSS for windows versi 22.
\end{abstract}

\section{Kata Kunci: Lingkungan Kerja, Motivasi, Kinerja Pegawai.}

\section{ABSTRACT}

This study aims to determine the effect of work environment on employee performance at the Department of Population and Civil Registration of Tangerang City. To determine the effect of motivation on employee performance at the Department of Population and Civil Registration of Tangerang City. To determine the effect of work environment and motivation on employee performance at the Office of Population and Civil Registration of Tangerang City. The research method used is a quantitative method with data collection techniques using a questionnaire instrument. The population in this study were all employees of the Department of Population and Civil Registration of Tangerang City, the sample technique used was using the slovin formula so that the sample obtained was 85 respondents. The data obtained from this study were analyzed using statistical methods with the help of the SPSS for windows version 22 program.

Keywords: Work Environment, Motivation, Employee Performance. 


\section{PENDAHULUAN}

\section{A. Latar Belakang Masalah}

Sumber daya manusia merupakan salah satu elemen terpenting yang akan memutar roda perusahaan terus berjalan. Meskipun ini tidak berhubungan langsung dengan keuangan atau pendapatan perusahaan, namun secara tidak langsung dapat berimbas pada kinerja perusahaan. Hal ini karena pada dasarnya sumber daya manusia lah yang bergerak mengelola perusahaan. Manajemen sumber daya manusia sangat berperan penting untuk mengatur pengelolaan sumber daya manusia dan sumber daya perusahaan agar memberikan hasil maksimal dan memiliki loyalitas tinggi. Selain itu juga akan memiliki profesionalitas terbaik yang dapat diandalkan untuk mencapai tujuan dan sasaran perusahaan.

Untuk mengembangkan kemampuan yang dimiliki oleh seorang pegawai, maka pegawai itu sendiri harus berminat mengembangkan kemampuanya, seperti kinerja mereka. Selain itu, pegawai juga harus di berikan fasilitas lingkungan kerja yang mendukung dan diberikan pula motivasi yang cukup. Jika kondisi lingkungan kerja dan motivasi sudah mencukupi, maka hasil dari kinerja mereka akan baik, namun jika kondisi lingkungan kerja dan motivasi mereka kurang baik, maka kinerja yang mereka hasilkan pun tidak akan sesuai dengan target perusahaan. Bagi perusahaan atau sebuah instansi pemerintahan penilaian kinerja sangat berguna untuk menilai kualitas, kuantitas, efesiensi perubahan, motivasi pegawai serta melakukan pengawasan dan perbaikan. Kinerja pegawai yang optimal sangat dibutuhkan guna menjaga kelangsungan hidup perusahaan dengan lingkungan yang baik dan motivasi yang baik pula akan dapat meningkatkan kinerja pegawai. Dalam usahanya untuk menghindari perilaku yang tidak di harapkan dan untuk meningkatkan kinerjanya, perusahaan atau sebuah instansi dapat menetapkan sanksi terhadap pelanggaran peraturan, sehingga perusahaan atau instansi tersebut dapat menghindari pengulangan - pengulangan perilaku yang tidak diinginkan tersebut. Namun salah satu faktor yang paling penting adalah kinerja pegawai itu sendiri. Efektif atau tidaknya kinerja pegawai dalam suatu perusahaan dapat dipengaruhi oleh beberapa faktor, faktor yang paling sering ditemukan yaitu Lingkungan kerja dan Motivasi kerja yang di ciptakan oleh perusahaan ataupun instasi itu sendiri. Dampaknya terhadap para pegawai adalah jika motivasi kerja dan lingkungan kerja dapat ditingkatkan dan dengan begitu kinerja kerjanya juga meningkat.

Dinas kependudukan dan pencatatan sipil kota Tangerang merupakan sebuah instansi yang berada di bawah naungan pemerintahan. Mempunyai tugas melaksanakan urusan pemerintahan daerah berdasarkan asas otonomi dan pembantuan di bidang kependudukan dan pencatatan sipil serta tugas lain yang diberikan walikota kota Tangerang sesuai dengan lingkup tugas dan fungsinya. Mempunyai kewenangan yaitu pelayanan pendaftaran penduduk, pemanfaatan dan penyajian database kependudukan,dan penyusunan profil kependudukan.

\section{B. Rumusan Masalah}

1. Bagaimana motivasi pada pengaruh lingkungan kerja terhadap kinerja pegawai pada Dinas Kependudukan dan Pencatatan Sipil Kota Tangerang?

2. Bagaimana motivasi terhadap kinerja pegawai pada Dinas Kependudukan dan Pencatatan Sipil Kota Tangerang?

3. Seberapa besar pengaruh lingkungan kerja dan motivasi terhadap kinerja pegawai pada Dinas Kependudukan dan Pencatatan Sipil Kota Tangerang? 


\section{Tujuan Penelitian}

1. Untuk mengetahui motivasi pada pada pengaruh lingkungan kerja terhadap kinerja pegawai pada Dinas Kependudukan dan Pencatatan Sipil Kota Tangerang

2. Untuk mengetahui motivasi terhadap kinerja pegawai pada Dinas Kependudukan dan Pencatatan Sipil Kota Tangerang

3. Untuk mengetahui seberapa besar pengaruh lingkungan kerja dan motivasi terhadap kinerja pegawai pada Dinas Kependudukan dan Pencatatan Sipil Kota Tangerang

\section{METODE PENELITIAN}

\section{Populasi}

Populasi dalam penelitian ini berjumlah 85 responden yaitu pegawai Dinas Kependudukan dan Pencatatan Sipil Kota Tangerang

\section{Sampel}

Teknik pengambilan sampling dalam penelitian ini adalah samplel jenuh, dimana semua anggota populasi dijadikan sebagai sampel. Dengan demikian sampel dalam penelitian ini berjumlah 85 responden.

\section{Jenis Penelitian}

Jenis penelitian yang dipakai adalah asosiatif, dimana tujuannya adalah untuk mengetahui mencari keterhubungan antara variabel independen terhadap variabel dependennya

\section{Metode Analisis Data}

Dalam menganalisis data digunakan uji validitas, uji reliabilitas, analisis regresi linier sederhana, koefisien korelasi, koefisien determinasi dan uji hipotesis.

\section{HASIL PENELITIAN DAN PEMBAHASAN}

\section{Uji Validitas Instrumen}

Uji validitas dimaksudkan untuk menguji pernyataan pada setiap butir pertanyaan pada kuesioner valid atau tidak. Untuk mengolah uji validitas, peneliti menggunakan SPSS versi 22 dengan kriteria sebagai berikut:

a. Jika rhitung > rtabel, dan bernilai positif, maka pertanyaan (indikator) tersebut dikatakan valid.

b. Jika rhitung < rtabel, dan bernilai negatif, maka pertanyaan (indikator) tersebut dikatakan tidak valid.

Sedangkan nilai $r$ tabel dalam penelitian ini dengan signifikasi 0,05 atau 5\% dan jumlah sampel yang dipakai $\mathrm{N}=85$, adalah:

Degree Of Freedom $=\mathrm{n}-2$

Degree Of Freedom $=85-2=83$

Jadi rtabel adalah $=0,213$

Adapun uji validitas untuk variabel Lingkungan Kerja (X1), Motivasi (X2), dan Kinerja Pegawai (Y) sebagai berikut:

Tabel 1

Hasil Uji Validitas Berdasarkan Variabel Lingkungan Kerja (X1)

\begin{tabular}{|c|c|c|c|}
\hline Item Kuesioner & $\mathrm{r}$ hitung & $\mathrm{r}$ tabel & Keputusan \\
\hline Pernyataan 1 & 0,430 & 0,213 & Valid \\
\hline Pernyataan 2 & 0,615 & 0,213 & Valid \\
\hline Pernyataan 3 & 0,594 & 0,213 & Valid \\
\hline Pernyataan 4 & 0,556 & 0,213 & Valid \\
\hline
\end{tabular}




\begin{tabular}{|c|c|c|c|}
\hline Pernyataan 5 & 0,589 & 0,213 & Valid \\
\hline Pernyataan 6 & 0,444 & 0,213 & Valid \\
\hline Pernyataan 7 & 0,617 & 0,213 & Valid \\
\hline Pernyataan 8 & 0,538 & 0,213 & Valid \\
\hline Pernyataan 9 & 0,509 & 0,213 & Valid \\
\hline Pernyataan 10 & 0,540 & 0,213 & Valid \\
\hline
\end{tabular}

Sumber: Data primer diolah, 2019

Berdasarkan data tabel diatas, variabel Lingkungan Kerja (X1) diperoleh nilai $r$ hitung lebih besar dari 0,213 atau $r$ hitung $>r$ tabel, dengan demikian maka semua item kuesioner dinyatakan valid. Untuk itu kuesioner yang digunakan layak untuk diolah sebagai data penelitian.

Tabel 2

Hasil Uji Validitas Berdasarkan Variabel Motivasi (X2)

\begin{tabular}{|c|c|c|c|}
\hline Item Kuesioner & r hitung & r tabel & \multicolumn{1}{l|}{ Keputusan } \\
\hline Pernyataan 1 & 0,561 & 0,213 & Valid \\
\hline Pernyataan 2 & 0,558 & 0,213 & Valid \\
\hline Pernyataan 3 & 0,551 & 0,213 & Valid \\
\hline Pernyataan 4 & 0,715 & 0,213 & Valid \\
\hline Pernyataan 5 & 0,421 & 0,213 & Valid \\
\hline Pernyataan 6 & 0,544 & 0,213 & Valid \\
\hline Pernyataan 7 & 0,540 & 0,213 & Valid \\
\hline Pernyataan 8 & 0,381 & 0,213 & Valid \\
\hline Pernyataan 9 & 0,508 & 0,213 & Valid \\
\hline Pernyataan 10 & 0,431 & 0,213 & Valid \\
\hline
\end{tabular}

Sumber: Data primer diolah,2019

Berdasarkan data tabel diatas, variabel Motivasi (X2) diperoleh nilai $r$ hitung lebih besar dari 0,213, atau $r$ hitung > $r$ tabel, dengan demikian maka semua item kuesioner dinyatakan valid. Untuk itu kuesioner yang digunakan layak untuk diolah sebagai data penelitian.

Tabel 3

Hasil Uji Validitas Berdasarkan Variabel Kinerja Pegawai (Y)

\begin{tabular}{|c|c|c|c|}
\hline Item Kuesioner & r hitung & r tabel & Keputusan \\
\hline Pernyataan 1 & 0,444 & 0,213 & Valid \\
\hline Pernyataan 2 & 0,577 & 0,213 & Valid \\
\hline Pernyataan 3 & 0,524 & 0,213 & Valid \\
\hline Pernyataan 4 & 0,634 & 0,213 & Valid \\
\hline Pernyataan 5 & 0,547 & 0,213 & Valid \\
\hline Pernyataan 6 & 0,595 & 0,213 & Valid \\
\hline Pernyataan 7 & 0,480 & 0,213 & Valid \\
\hline Pernyataan 8 & 0,449 & 0,213 & Valid \\
\hline Pernyataan 9 & 0,523 & 0,213 & Valid \\
\hline Pernyataan 10 & 0,637 & 0,213 & Valid \\
\hline
\end{tabular}

Sumber: Data primer diolah,2019

Berdasarkan data tabel diatas, variabel Kinerja Pegawai (Y) diperoleh nilai r hitung lebih besar dari 0,213, atau $\mathrm{r}$ hitung > $\mathrm{r}$ tabel, dengan demikian maka semua item kuesioner dinyatakan valid. Untuk itu kuesioner yang digunakan layak untuk diolah sebagai data penelitian. 


\section{Uji Reliabilitas Instrumen.}

Pengujian reliabilitas dimaksudkan untuk menguji suatu kuesioner reliabel atau handal atau tidak. Menurut Sugiyono (2017:121), "Uji reliabilitas adalah instrumen yang apabila digunakan beberapa kali untuk mengukur obyek yang sama, akan menghasilkan data yang sama. Atau pengukuran yang menunjukkan stabilitas dan konsistensi dari suatu variabel". Adapun kriteria atau ketentuan dalam memutuskan pernyataan tersebut reliabel atau tidak, berikut ini ketentuannya:

Jika $r$ hitung $>r$ tabel dikatakan reliable

Jika $r$ hitung $<\mathrm{r}$ tabel dikatakan unreliable

Hasil uji reliabilitas dalam penelitian ini dilakukan dengan menggunakan software SPSS versi 22, yang hasilnya sebagai berikut:

Tabel 4

Hasil Uji Reliabilitas Variabel Independen dan Dependen.

\begin{tabular}{|c|l|c|c|c|}
\hline No & \multicolumn{1}{|c|}{ Variabel } & r hitung & r tabel & Keputusan \\
\hline 1 & Lingkungan Kerja (X1) & 0,730 & 0,60 & Reliabel \\
\hline 2 & Motivasi (X2) & 0,705 & 0,60 & Reliabel \\
\hline 3 & Kinerja Pegawai (Y) & 0,724 & 0,60 & Reliabel \\
\hline
\end{tabular}

Sumber: Data primer diolah,2019

Berdasarkan hasil pengujian pada tabel diatas, menunjukkan bahwa variabel Lingkungan Kerja (X1), Motivasi (X2), dan Kinerja Pegawai (Y) dinyatakan reliabel, hal itu dibuktikan dengan masing-masing variabel memiliki nilai $r$ hitung $>r$ tabel

\section{PEMBAHASAN HASIL PENELITIAN}

\section{Pengaruh Lingkungan Kerja Terhadap Kinerja Pegawai}

Berdasarkan hasil statistik, diperoleh nilai koefisien korelasi sebesar 0,458 artinya kedua variabel mempunyai tingkat pengaruh yang sedang. Nilai determinasi atau kontribusi pengaruh lingkungan kerja (X1) terhadap kinerja pegawai (Y) adalah sebesar 0,209 atau sebesar 20,9\% sedangkan sisanya 79,1\% dipengaruhi oleh faktor lain. Hal ini menunjukkan bahwa lingkungan kerja yang baik akan meningkatkan kinerja pegawai. Uji hipotesis diperoleh $\mathrm{t}$ hitung $>\mathrm{t}$ tabel atau $(4,690>1,989)$, hal ini diperkuat dengan probability signicancy $0,000<0,05$, dengan demikian H_o1 ditolak dan H_a1 diterima artinya terdapat pengaruh positif dan signifikan secara parsial antara lingkungan kerja terhadap kinerja pegawai.

\section{Pengaruh Motivasi Terhadap Kinerja Pegawai}

Berdasarkan hasil statistik, diperoleh nilai koefisien korelasi sebesar 0,608 artinya kedua variabel mempunyai tingkat pengaruh yang kuat. Nilai determinasi atau kontribusi pengaruh motivasi (x2) terhadap kinerja pegawai (Y) adalah sebesar 0,370 atau sebesar $37 \%$ sedangkan sisanya $63 \%$ dipengaruhi oleh faktor lain. Hal ini menunjukkan bahwa motivasi yang baik akan meningkatkan kinerja pegawai. Uji hipotesis diperoleh t hitung $>\mathrm{t}$ tabel atau $(6,975>1,989)$, hal ini diperkuat dengan probability signicancy $0,000<$ 0,05, dengan demikian H_o2 ditolak dan H_a2 diterima artinya terdapat pengaruh positif dan signifikan secara parsial antara motivasi terhadap kinerja pegawai.

\section{Pengaruh Lingkungan Kerja dan Motivasi Secara Bersama-sama Terhadap Kinerja Pegawai}

Berdasarkan hasil penelitian, menunjukkan bahwa Lingkungan Kerja (X1) dan Motivasi (X2) berpengaruh positif terhadap Kinerja Pegawai Dinas Kependudukan dan Pencatatan Sipil Kota Tangerang dengan diperoleh persamaan regresi $\mathrm{Y}=14,068+$ 
0,166X_(1 )+0,487X_2. Hasil analisis regresi ini menunjukkan koefisien dari masingmasing variabel bertanda positif, artinya semakin tinggi lingkungan kerja dan motivasi, maka akan semakin tinggi pula kinerja pegawai. Sedangkan nilai korelasi atau tingkat pengaruh antara variabel bebas dengan variabel terikat diperoleh sebesar 0,624 artinya memiliki memiliki pengaruh yang kuat. Nilai determinasi atau kontribusi pengaruh lingkungan kerja dan motivasi sebesar 39\% sedangkan sisanya sebesar $61 \%$ dipengaruhi oleh faktor lain yang tidak digunakan dalam penelitian ini. Pengujian hipotesis diperoleh F hitung $>$ Ftabel atau $(26,203>3,110)$, hal tersebut juga diperkuat dengan probability significancy $0,000<0,05$. Dengan demikian H_o3 ditolak dan H_a3 diterima. Artinya terdapat pengaruh positif dan signifikan secara simultan antara lingkungan kerja dan motivasi terhadap kinerja pegawai.

\section{V.PENUTUP}

\section{Kesimpulan}

a. Berdasarkan perhitungan koefisien korelasi secara parsial antara variabel lingkungan kerja (x_1) terhadap kinerja pegawai $(\gamma)$, diperoleh nilai $\mathrm{R}$ (koefisien korelasi) 0,458 artinya kedua variabel memiliki tingkat pengaruh atau hubungan yang sedang. Melalui hasil perhitungan yang telah dilakukan diperoleh nilai t hitung $>\mathrm{t}$ tabel atau $(4,690>$ $1,989)$ hal tersebut juga diperkuat dengan nilai $\rho$ value $<$ Sig. 0,05 atau $(0,000<0,05)$.

b. Berdasarkan perhitungan koefisien korelasi secara parsial antara variabel Motivasi (x_2) terhadap variabel terikat yaitu Kinerja Pegawai $(\gamma)$, diperoleh nilai R (koefisien korelasi) 0,608 artinya kedua variabel memiliki tingkat pengaruh atau hubungan yang kuat. Melalui hasil perhitungan yang telah dilakukan diperoleh nilai $t$ hitung $>\mathrm{t}$ tabel atau $(6,975>1,989)$ hal tersebut juga diperkuat dengan nilai $\rho$ value $<$ Sig. 0,05 atau $(0,000<0,05)$.

c. Berdasarkan hasil penelitian dengan menggunakan analisis koefisien regresi berganda didapatkan persamaan regresi $\mathrm{Y}=14,068+0,166 \mathrm{X} \_(1)+0,487 \mathrm{X} \_2$. Kemudian dengan menggunakan analisis koefisien korelasi berganda (Multiple Correlation) $\mathrm{R}$ (koefisien kolerasi) sebesar 0,624 artinya variabel Lingkungan Kerja (x_1) dan Motivasi (x_2) mempunyai tingkat pengaruh atau hubungan yang kuat terhadap Kinerja Pegawai $(\gamma)$. Dan dari hasil pengujian hipotesis (Uji F) didapatkan nilai $F$ hitung $>\mathrm{F}$ tabel atau $(26,203>3,110)$, hal ini juga diperkuat dengan $\rho$ value $<$ Sig.0,05 atau $(0,000<0,05)$.

\section{Saran}

a. Dari sisi lingkungan kerja, dekorasi ruangan perlu ditata sedemikian rupa demi menciptakan rasa nyaman pegawai dalam bekerja, selain itu pihak instansi perlu meningkatkan ketersediaan fasilitas kantor yang lengkap agar dapat menunjang keberlangsungan pegawai dalam bekerja.

b. Dari sisi motivasi, seharusnya para atasan pada Dinas Kependudukan dan Pencatatan Sipil Kota Tangerang bisa melihat kinerja para pegawainya dalam melaksanakan tugasnya, seperti dilihat dari hasil pernyataan kuesioner yang diberikan, masih banyak para atasan yang tidak memberikan penghargaan kepada para pegawainya yang sudah bekerja secara efektif, bahkan jika pegawai telah menjalankan tugasnya dengan hasil yang memuaskan para atasan tidak memberikan pujian kepada bawahannya yang seharusnya diberikan untuk memotivasi para pegawainya.

c. Dari sisi kinerja pegawai, untuk meningkatkan kinerja para pegawainya seharusnya Dinas Kependudukan dan Pencatatan Sipil Kota Tangerang memberikan target kepada pegawai dalam menyelesaikan pekerjaannya sehingga para pegawai dapat 
menyelesaikan pekerjaan sesuai dengan waktu yang telah diberikan.

\section{DAFTAR PUSTAKA}

Abdullah, M, "Manajemen dan Evaluasi Kinerja Karyawan", Yogyakarta: Aswaja Pressindo, 2014.

Anton, \& Irjayanti, M, “Manajemen”, Bandung: Mardika Group, 2014.

Effendy, A. A., Sunarsi, D., Kristianti, L. S., Irawati, L., \& Wahyitno, W. (2020). Effect Of Giving Reward and Motivation to Employee Productivity In PT. Sinar Kencana Jaya In Surabaya. HUMANIS (Humanities, Management and Science Proceedings), $1(1)$.

Fattah, H, “Kepuasan Kerja dan Kinerja Pegawai”, Yogyakarta: Elmatera, 2017.

Gunartin, G., Mulyanto, E., \& Sunarsi, D. (2020). The Role Analysis of Waste Bank in Improving the Community's Creative Economy (Study at Ketumbar Pamulang Waste Bank). Budapest International Research and Critics Institute (BIRCI-Journal): Humanities and Social Sciences, 3(4), 3262-3269.

Haque, MG., Munawaroh, Sunarsi, D., (2020). Analysis of SMEs Culinary Marketing Strategy During Covid 19 Pancemic: A Study at "Sate Bebek Cilegon" Resto in Cilegon, Banten. International Journal of Education, Information Technology, and Others. Vol.3. Issue 2

Kembara, M. D., Hanny, R., Gantina, N., Kusumawati, I., Budimansyah, D., Sunarsi, D., \& Khoiri, A. (2020). Scientific Literacy Profile Of Student Teachers On Science For All Context. Solid State Technology, 63(6), 5844-5856.

Khoiri, A. (2016). Local Wisdom PAUD to Grow Student's Soft Skills (Study Cash: Development RKH On Science Learning). Indonesian Journal of Early Childhood Education Studies, 5(1), 14-17.

Mangkunegara, A, "Manajemen Sumber Daya Manusia”, Bandung: Remaja Rosdakarya, 2013.

Rozi, A., Agustin, F., Hindriari, R., Rostikawati, D., \& Akbar, I. R. (2020). The Effect Of Leadership On Employee Performance at PT. Stella Satindo In Jakarta. HUMANIS (Humanities, Management and Science Proceedings), 1(1).

Rozi, A., Agustin, F., Hindriari, R., Rostikawati, D., \& Akbar, I. R. (2020). The Effect Of Leadership On Employee Performance at PT. Stella Satindo In Jakarta. HUMANIS (Humanities, Management and Science Proceedings), 1(1).

Sarwani, S., Akbar, I. R., Handoko, A. L., \& Ilham, D. (2020). Pengaruh Pelatihan dan Motivasi terhadap Produktivitas Kerja Karyawan pada PT. Lion Mentari Airlines Bandara Internasional Soekarno Hatta Cengkareng. Jurnal Ilmu Komputer dan Bisnis, 11(2a), 91-100.

Sedarmayanti, "Manajemen Sumber Daya Manusia reformasi Birokrasi dan Manajemen Pegawai Negeri Sipil”, Bandung: PT Refika Aditama, 2016.

Sofyan, S., Prasada, D., \& Akbar, I. R. (2020). Pengaruh Motivasi, Lingkungan Kerja dan Kepuasan Kerja Terhadap Kinerja Guru SMP/MTs Muhammadiyah Cabang Sawangan. Jurnal Ilmu Komputer dan Bisnis, Volume 11, Issue 2a, Pages 44-55

Sunarsi, D. (2016). Hubungan Pengendalian Diri dengan Prestasi Belajar (Studi Kasus pada Mahasiswa Semester 1, Kelas 510 dan 511, Tahun Akademik 2015/2016, Program Studi Manajemen, Universitas Pamulang, Tangerang Selatan). 